\title{
Genotypic Variations may Elucidate Resistance to Plasmodium falciparum Infection In Vitro
}

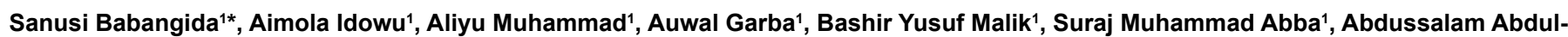
Aziz $^{1}$, John Adejor ${ }^{1,3}$ and Oniovokukor O Kite ${ }^{1,2}$

${ }^{1}$ Department of Biochemistry, Ahmadu Bello University, Zaria, Nigeria

${ }^{2}$ Department of Applied Biochemistry, Nnamdi Azikiwe University, Awka, Nigeria

${ }^{3}$ Department of Biochemistry, University of Agriculture, Makurdi, Nigeri

\begin{abstract}
Plasmodium falciparum malaria remains a significant cause of human suffering, and most malaria-related morbidity and mortality occurs in children living in sub-Sahara Africa. Evolutionary pressure has explained that various erythrocyte polymorphisms could protect against severe complications and death from Plasmodium falciparum malaria. Several mechanisms have been proposed to explain the protection of hemoglobin AS and SS from severe Plasmodium falciparum malaria. Sickle trait; the heterozygous and homozygous state of normal hemoglobin $A(H \mathrm{bA})$ could confer protection against malaria in Africa. In the present study, we cultured Plasmodium falciparum infected red blood cells from AA, AS and SS for six days. During the six days period, the level of parasite load (Parasitemia) and the activity of arginase released by the parasite were monitored on daily basis. Result obtained shows a significant $(P<0.05)$ increase in both the level of parasite load and the activity of arginase. This increase was found to be higher in AA genotype while lower in both SS and AS, but with AS been much lower. The mechanisms by which sickle trait confer such malaria protection might be as a result of change in structural conformation that alter with the parasite ability to invade into the cells through the membrane protein receptors and hence a decrease in its activity in both AS and SS respectively.
\end{abstract}

Keywords: Genotype; Infection; Plasmodium falciparum; Arginase; Parasitemia

\section{Introduction}

Malaria remains one of the most important public health problems in the world, with about 3 billion people at risk of contracting the disease and 781,000 deaths estimated annually [1]. The global burden of human malaria is caused almost exclusively by two species of parasites: Plasmodium falciparum and Plasmodium vivax [1]. Plasmodium falciparum malaria remains a significant cause of human suffering, and most malaria-related morbidity and mortality occurs in children living in sub-Saharan Africa [2]. In regions highly endemic for Plasmodium falciparum infection, the majority of children with malaria present with a mild form of the disease with only a small percentage of those infected go on to develop severe disease and subsequently die of it [3]. This is attributed in large part to host resistance factors that have developed during the several thousand years of high exposure to $P$. falciparum malaria [3]. Since children who are susceptible to severe malaria die before reproductive age, genes that confer resistance to severe disease should be in the population living in sub-Saharan Africa $[3,4]$. The protective effect of certain red cell polymorphisms, such as hemoglobin $S(\mathrm{HbS})$, $\alpha$-thalassemia, $\beta$-thalassemia, glucose6-phosphate dehydrogenase (G6PD) deficiency, hemoglobin E, and ovalocytosis, against severe $P$. falciparum malaria has been suggested because epidemiological evidence links the distribution of these polymorphisms to areas currently or historically highly endemic for malaria [1].

Sickle cell syndromes, also collectively often referred to as sickle cell disease (SCD), comprise a group of clinically significant haemoglobinopathies in which the sickle gene is inherited from at least one parent [5]. Its prevalence, known to be found at 20 to $25 \%$ in Africa and may reach up to $40 \%$ in some regions [6]. It was suggested that sickle cell trait carrier protects from the most severe forms of malaria, and the beneficial effect is principally observed in children [6]. The sickle cell trait (HbAS), comprising heterozygous carrier of hemoglobin $(\mathrm{Hb}) \mathrm{S}$, which is as a result of a valine substitution for glutamic acid at position 6 of the hemoglobin chain [7]. HbAS provides carriers with a high degree of protection against severe Plasmodium falciparum malaria during early life, which explains the relatively high penetrance of this mutation in some areas reaching $30 \%$ in sub-Saharan African communities exposed to high rates of infection with $P$. falciparum [8]. Molecular-genetic evidence suggests that this mutation has been selected independently at least five times in Africa, Arabia, and India [9]. HbAS has also been reported to protect against $P$. falciparum malaria-related morbidity in general, as well as against elevated parasitemia and/or infection per se [8].

However, the mechanisms mediating this resistance remain unclear. It has been proposed that the protective effect of this genetic trait might be partly due to impaired growth of parasites inside sickle red blood cells and may additionally involve a modulation of the immune response leading to a faster acquisition of immunity $[2,10]$. Invasion of human red blood cells (RBCs) by Plasmodium falciparum merozoites is a complex, multistage process involving proximity reactions, contact, reorientation, secretion, and internalization events, the molecular nature of which is currently the subject of intense research [11]. Another proposed mechanism of protection against falciparum malaria is based on reducing the fraction of RBCs vulnerable to parasite invasion, with the consequent decrease in the incidence of high parasitemia and severe malaria [11]. Another research finding suggested that protein palmitoylation in asexual-stage of $P$. falciparum parasites plays a vital role in cytoadherence, drug resistance, signaling,

*Corresponding author: Sanusi Babangida, Department of Biochemistry, Ahmadu Bello University, Zaria, Nigeria, Tel: 2347065655363; E-mail: ssskatsayal@gmail.com or bskatsayal@abu.edu.ng

Received June 24, 2017; Accepted July 11, 2017; Published July 14, 2017

Citation: Babangida S, Idowu A, Muhammad A, Garba A, Malik BY, et al. (2017) Genotypic Variations may Elucidate Resistance to Plasmodium falciparum Infection In Vitro. Clin Med Biochem 3: 131. doi:10.4172/2471-2663.1000131

Copyright: $\odot 2017$ Babangida S, et al. This is an open-access article distributed under the terms of the Creative Commons Attribution License, which permits unrestricted use, distribution, and reproduction in any medium, provided the original author and source are credited. 
development, and invasion as over 400 palmitoylated proteins were identified [12]. Moreover these protection has been attributed in some studies to defective invasion or growth of the parasite in the mutant erythrocytes increased osmotic resistance, enhanced oxidant radical production due to unpaired globin chains, increased sickling, ionic unbalances or membrane rigidity, or molecular defects have been suggested as underlying mechanisms explaining impaired growth of the parasite in the mutant RBCs [13]. Lamonte et al. [12] suggested that dysregulated microRNA (miRNA) composition, of either heterozygous HbAS or homozygous HbSS erythrocytes, contributes to resistance against $P$. falciparum. Further, the Hemoglobin $\mathrm{C}$ allele was shown to provide resistance to $P$. falciparum by altering the cell-surface properties of infected erythrocytes, resulting in abnormal display of the cytoadherence ligand PfEMP-1, and leading to decreased cell adhesion, impaired rosetting, and reduced hemagglutination [14]. P. falciparum was also reported to grow poorly within homozygous sickle (HbSS) erythrocytes [14]. The protective effect of HbAS was remarkably specific for falciparum malaria, having no significant impact on other parasite [10]. In this study, we attempted to reconcile some of the contradictory data in the literature through comparative study on sickle cell heterozygous and homozygous resistivity to $P$. falciparum infection. The pathogenic course of Plasmodium falciparum infection is characterized with some clinical manifestations which includes hypoglycemia, lactic acidosis, hemolytic anemia, hemoglobinuria, and hypoargininemia [15]. Decrease level of L-arginine does not affect its influx kinetics of into erythrocytes but it correlate with decreased levels of immunity and nitric oxide (NO) production [15]. The depletion of $\mathrm{L}$-arginine is achieved by the help of enzyme arginase from the malarial parasite, which catalyzes the hydrolysis of the side chain guanidinium group to form L-ornithine and urea [16]. Increased arginase activity characterizes the alternative immune response, which down regulates inflammation and tissue damage while upregulating angiogenesis and tissue repair mechanisms [17]. Such conditions favor parasite growth through suppressed $\mathrm{T}$ cell and inflammatory responses to pathogens and increased concentrations of L-ornithine-derived polyamines, which facilitate cellular proliferation [18]. In our work, we examine the activity of this enzyme in cultured blood cells from three most common genotypes alongside parasite proliferation (Figure 2).

\section{Ethical statement}

Ethical permission for the study was granted by Ahmadu Bello University teaching hospital (ABUZ). Individual written informed consent was provided by all study participants or their parents.

\section{Materials and Methods}

\section{Materials and reagents}

RPMI 1640 media (Sigma Aldrich, Germany), Giemsa stain (Sigma Aldrich, Germany), Ninhydrin (sigma Aldrich, Germany), L-arginine (Sigma Aldrich, Germany).

\section{Sample collection}

Plasmodium falciparum infected and uninfected blood samples (AA, AS, SS) from healthy and infected patient was obtained from Ahmadu Bello University Sickbay, Zaria. The sample was collected with the help of a certified medical personnel.

\section{Media preparation}

$\mathrm{O}+$ blood was collected, centrifuged at $10000 \mathrm{rpm}$ for $20 \mathrm{~min}$ at $4^{\circ} \mathrm{C}$.
Serum was kept in aliquots and inactivated by keeping at $56^{\circ} \mathrm{C}$ water bath (30 min). $10 \mathrm{ml}$ inactivated $\mathrm{O}+$ human serum was added to $90 \mathrm{ml}$ of incomplete media ( $96 \mathrm{ml}$ of stock RPMI 1640 media containing $4 \mathrm{ml}$ of $5 \%$ sodium carbonate solution) making $100 \mathrm{ml}$ of working media.

\section{Preparation of red blood cells and culture}

$\mathrm{O}+$ blood was collected, centrifuge $(1500 \mathrm{rpm}$ for $10 \mathrm{~min}$ ) at room temperature. Plasma and buffy coat layer was removed and this washing process was repeated 3 times in an incomplete media. Equal amount of complete media was added to the washed red blood cells and stored at $4^{\circ} \mathrm{C}$ in refrigerator.

Infected red blood cell culture: 50\% suspension of infected cells (Plasmodium falciparum) in complete media (containing 15\% serum) was added to equal amount of prepared uninfected $\mathrm{O}+$ red blood cells to obtained an initial parasitemia ranged from 0.5 to $1.0 \%$. The mixture was diluted with complete media to get $5 \%$ cell suspension (5\% hematocrit). Culture was kept in $\mathrm{CO}_{2}$ incubator at $37^{\circ} \mathrm{C}$ in Mary Hallaway Teaching Laboratories (MHTL).

\section{Estimation of parasite load}

After every 24 hours a portion of the cultured cells was collected (by removing the media without disturbing the cells) and a thin smear was prepared using Giemsa stain for examination of parasite load under light microscope. Fresh complete media (containing 10\% serum) was added, mixed properly, and kept in the incubator. And \% parasite load was counted using the formula below and erythrocyte containing $\geq 2$ parasite is still counted as one infected erythrocyte.

\% Parasitemia $=($ No. of infected RBCs $) /$ (No. of uninfected RBCs) $\times 100$

\section{Estimation of arginase activity}

This is based on the facts that arginase act on it substrate (arginine) to produce ornithine and urea, under boiling temperature. A portion of the cultured cells was used to determine the activity of arginase spectrophotometrically by measuring the formation of L-Ornithine at $515 \mathrm{~nm}$ with ninhydrin.

\section{Statistical analysis}

The data was analyzed using one way ANOVA followed with a multiple comparison test (Bonferroni) using statistical package for social science (SPSS) and the result was presented as mean \pm standard deviation.

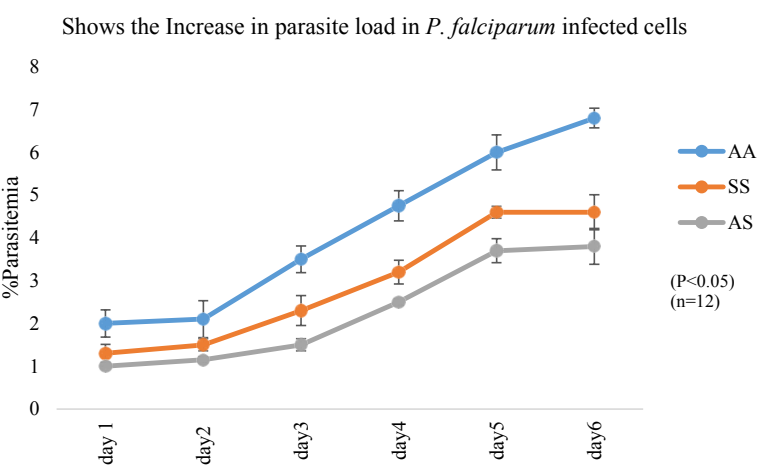

Figure 1: Increased parasite load in $P$. falciparum infected cells. Statistic shows the difference is significant at $P<0.05$ and $n=12$ is the number of times each genotype was carried out. 
Citation: Babangida S, Idowu A, Muhammad A, Garba A, Malik BY, et al. (2017) Genotypic Variations may Elucidate Resistance to Plasmodium falciparum Infection In Vitro. Clin Med Biochem 3: 131. doi:10.4172/2471-2663.1000131

\section{Results}

Progressive increased parasite load in $P$. falciparum infected cells

There was a significant $(\mathrm{P}<0.05)$ increase in the level of parasite load in all the genotypes (AA, AS, SS) from day 1 to day 5 of the experiment period. This increase was observed to be higher in AA followed by SS and very slower in AS genotype (Figure 1 and Plates 1-3). This could simply explain the ease at which the parasite proliferate in AA genotype and its ability to further invade into the uninfected cells present in the culture medium.

\section{Progressive increased arginase activity in $P$. falciparum infected cells}

The activity of arginase was also found to increase with increasing parasite load and in accordance to the previous order with AA, SS and AS respectively. This could also explain in addition, the competitive advantage by the parasite to source more of its nutrient requirement for survival and further weakens the immune power by suppressing the activity of nitric oxide synthase

\section{Discussion}

The estimated parasitemia level shows a significant $(\mathrm{P}<0.05)$ increase as increase in number of days but these increment varies with as in most common blood genotype (AA, SS, AS). SS and AS genotype resistance to plasmodium infection was predicted to be as a result of distortion in the membrane of the cells, as a result the morphology of the binding receptors on the surface of red blood cells membrane, therefore cannot be recognize by Plasmodium falciparum binding ligand (pfbl) [1]. This mechanism help to reduce level of plasmodium infection in heterozygous and homozygous sickle cell allele [19].

Arginase released by Plasmodium falciparum depend on level of parasitemia in the blood, thus causes an increased in haemoglobin degradation and release of various amino acid for parasite metabolism [15]. Significant $(\mathrm{P}<0.05)$ increase in the activity of arginase in this study signify low levels of L-arginine and this correlate with decreased immunity and nitric oxide (NO) production [10]. The depletion of L-arginine in culture is achieved by an arginase from the malarial parasite, which catalyzes the hydrolysis of the side chain guanidinium group to form L-ornithine and urea [20]. Increased arginase activity characterizes the alternative immune response, which down-regulates inflammation and tissue damage while up-regulating angiogenesis and tissue repair mechanisms [15]. Such conditions favor parasite growth through suppressed $\mathrm{T}$ cell and inflammatory responses to pathogens and increased concentrations of $\mathrm{L}$-ornithine-derived polyamines, which facilitate cellular proliferation [1]. Strong positive correlation between arginase activity and increase parasite proliferation demonstrate adaptive mechanism for parasite survival.

\section{Conclusion and Recommendation}

The present study demonstrate Plasmodium falciparum infection to confers a genetic based restrictive survival based on changes in parasite count and arginase release monitored over the duration of this experiments. Therefore, changes in genetic makeup can alter with morphological orientation of some vital structures that play a crucial role in the survival of the organism. And since malaria parasite (Plasmodium falciparum) releases arginase into the system in order to sustain it survival, development of specific arginase inhibitors can be a useful adjuvants in the treatment of malarial infections.
Shows the Increase in arginase activity in $P$. falciparum infected cells

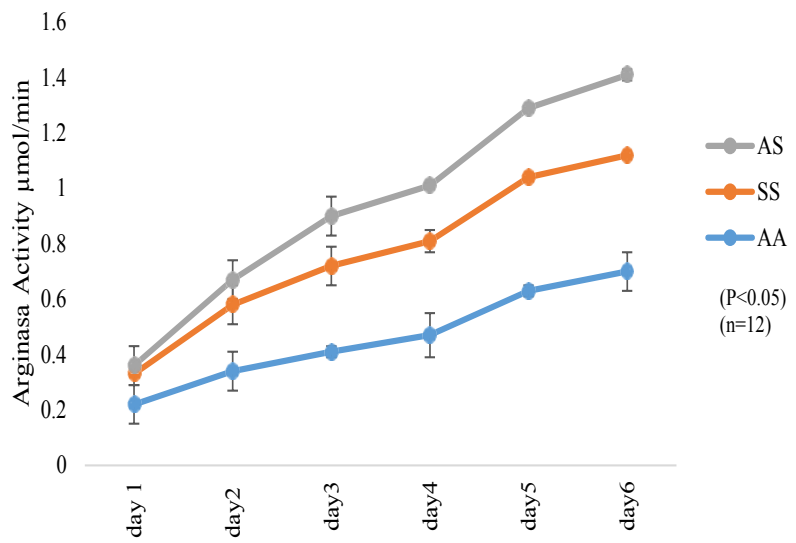

Figure 2: Increased arginase activity in $P$. falciparum infected cells. Statistic shows the difference is significant at $P<0.05$ and $n=12$ is the number of times each genotype was carried out.

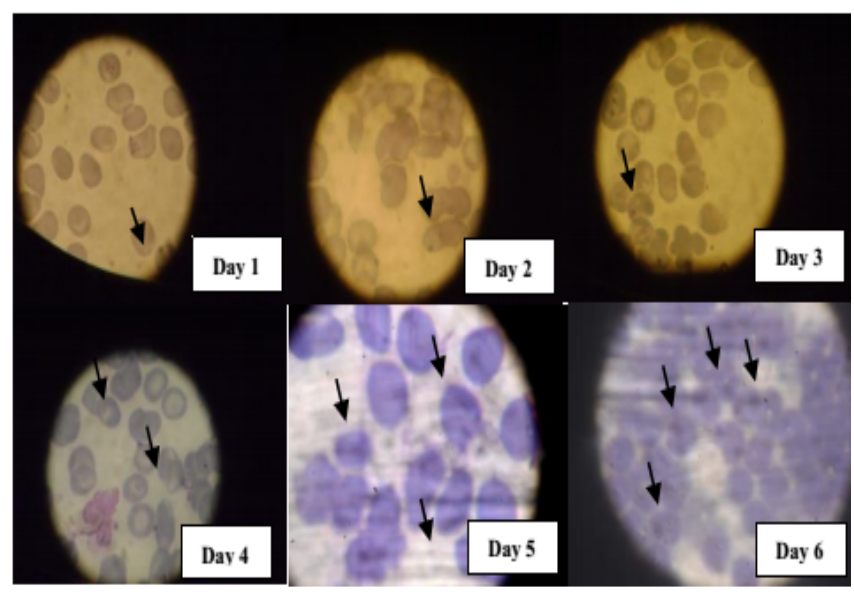

Plate 1: Photomicrograph showing parasites under light microscope in AA genotype (100X), arrow showing parasitized cells.

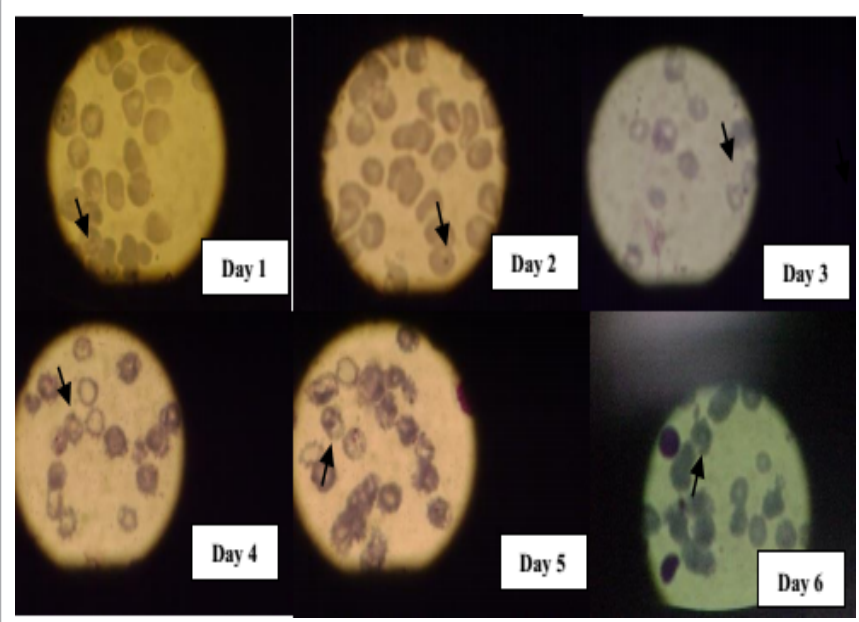

Plate 2: Photomicrograph showing parasites under light microscope in SS genotype (100X), arrow showing parasitized cells. 
Citation: Babangida S, Idowu A, Muhammad A, Garba A, Malik BY, et al. (2017) Genotypic Variations may Elucidate Resistance to Plasmodium falciparum Infection In Vitro. Clin Med Biochem 3: 131. doi:10.4172/2471-2663.1000131

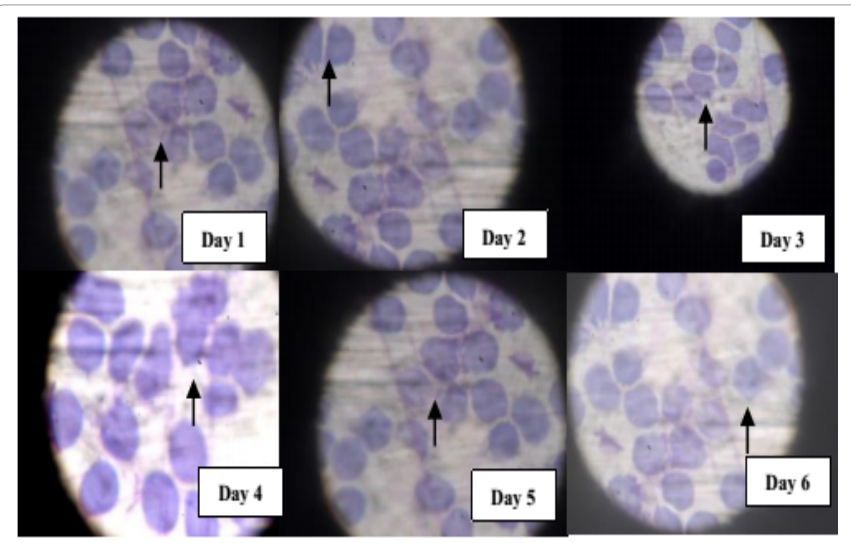

Plate 3: Photomicrograph showing parasites under light microscope in AS genotype (100X), arrow showing parasitized cells.

\section{References}

1. Castro-Gomes T, Mourão LC, Melo GC, Monteiro WM, Lacerda MV, et al (2014) Potential Immune Mechanisms Associated with Anemia in Plasmodium vivax Malaria : a Puzzling Question. Infect Immun 82: 3990-4000.

2. Matondo DW, Mavoungou E, Deloron P, Theisen M, Ntoumi F (2006) Distribution of IgG subclass antibodies speci W c for Plasmodium falciparum glutamate-rich-protein molecule in sickle cell trait children with asymptomatic infections 112: 92-98.

3. Lell B, Schmidt-ott RJ, Lehman LG, Luckner D, Greve B, et al. (1998) The Role of Red Blood Cell Polymorphisms in Resistance and Susceptibility to Malaria. Clin Infect Dis 1999: 794-799.

4. Cappadoro BM, Giribaldi G, Brien EO, Turrini F, Mannu F, et al. (1998) Early Phagocytosis of Glucose-6-Phosphate Dehydrogenase (G6PD)-Deficient Erythrocytes Parasitized by Plasmodium falciparum May Explain Malaria Protection in G6PD Deficiency. America (NY) 92: 2527-2535.

5. Ballas SK (1998) Sickle cell disease: clinical management. Baillieres Clin Haematol 11: 185-214.

6. Ntoumi F, Ekala MT, Makuwa M, Lekoulou F, Mercereau-Puijalon O, et al. (2002) Sickle cell trait carriage: imbalanced distribution of IgG subclass antibodies reactive to Plasmodium falciparum family-specific MSP2 peptides in serum samples from Gabonese children. Immunol Lett 84: 9-16.

7. Elagouz M, Jyothi S, Gupta B, Sivaprasad S (2010) Sickle cell disease and the eye: old and new concepts. Survey of Ophthalmology 55: 359-377.
8. Cabrera G, Cot M, Migot-nabias F, Kremsner PG, Deloron P, et al. (2005) The Sickle Cell Trait Is Associated with Enhanced Immunoglobulin G Antibody Responses to Plasmodium falciparum Variant Surface Antigens. J Infect Dis 191: 1631-1638.

9. Diakite AS, Cholera R, Brittain NJ, Gillrie MR, Lopera-mesa TM, et al. (2007) Impaired cytoadherence of Plasmodium falciparum-infected erythrocytes containing sickle hemoglobin. PNAS 105: 991-996.

10. Williams TN, Mwangi TW, Wambua S, Alexander ND, Kortok M (2005) Sickle cell trait and the risk of Plasmodium falciparum malaria and other childhood diseases. The Journal of Infectious Diseases 192: 178-186.

11. Tiffert T, Lew VL, Ginsburg H, Krugliak M, Croisille L, et al. (2005) The hydration state of human red blood cells and their susceptibility to invasion by Plasmodium falciparum. Blood 105: 4853-4860.

12. Jones ML, Collins MO, Goulding D, Choudhary JS, Rayner JC (2012) Analysis of protein palmitoylation reveals a pervasive role in Plasmodium development and pathogenesis. Cell Host \& Microbe 12: 246-258.

13. Ayi K, Turrini F, Piga A, Arese P (2004) Enhanced phagocytosis of ringparasitized mutant erythrocytes: a common mechanism that may explain protection against falciparum malaria in sickle trait and beta-thalassemia trait. Blood 104: 3364-3371.

14. LaMonte G, Philip N, Reardon J, Lacsina JR, Majoros W (2012) Translocation of sickle cell erythrocyte microRNAs into Plasmodium falciparum inhibits parasite translation and contributes to malaria resistance. Cell Host \& Microbe 12: 187-199.

15. Martins YC, Zanini GM, Frangos JA, Carvalho LJ (2012) Efficacy of different nitric oxide-based strategies in preventing experimental cerebral malaria by Plasmodium berghei ANKA. PloS ONE 7.

16. Yeo TW, Lampah DA, Tjitra E, Gitawati R, Kenangalem E (2009) Relationship of cell-free hemoglobin to impaired endothelial nitric oxide bioavailability and perfusion in severe falciparum malaria. The Journal of Infectious Diseases 200: 1522-1529.

17. Kotepui M, Piwkham D, PhunPhuech B, Phiwklam N, Chupeerach C, et al (2015) Effects of malaria parasite density on blood cell parameters. PLoS ONE 10.

18. Cowman AF, Berry D, Baum J (2012) The cellular and molecular basis for malaria parasite invasion of the human red blood cell. J Cell Biol 198: 961-971.

19. Williams TN, Mwangi TW, Wambua S, Alexander ND, Kortok M, et al. (2005) Sickle cell trait and the risk of Plasmodium falciparum malaria and othe childhood diseases. The Journal of Infectious Diseases 192: 178-186.

20. Hanada K, Palacpac NM, Magistrado PA, Kurokawa K, Rai G (2002) Plasmodium falciparum phospholipase $\mathrm{C}$ hydrolyzing sphingomyelin and lysocholinephospholipids is a possible target for malaria chemotherapy. Journal of Experimental Medicine 195: 23-34. 